\title{
Non-Random Distribution of Human Orofacial Clefts in Ghana: Gene-Environment Interactions
}

\author{
Lord Jephthah Joojo Gowans ${ }^{1,2,3}{ }^{*}$, Solomon Obiri-Yeboah ${ }^{2,3}$, Alexander Acheampong Oti2,3, \\ Fareed Kow Nanse Arthur ${ }^{1}$, Peter Twumasi' ${ }^{1}$, Pius Agbenorku${ }^{4}$, Gyikua Plange-Rhule ${ }^{3,5}$, \\ Peter Donkor ${ }^{2,3,4}$
}

${ }^{1}$ Department of Biochemistry and Biotechnology, Kwame Nkrumah University of Science and Technology (KNUST), Kumasi, Ghana ${ }^{2}$ Department of Oral and Maxillofacial Surgery, Dental School, KNUST, Kumasi, Ghana

${ }^{3}$ Cleft-Craniofacial Clinic, Komfo Anokye Teaching Hospital (KATH), Kumasi, Ghana

${ }^{4}$ Department of Surgery, School of Medical Sciences, KNUST, Kumasi, Ghana

${ }^{5}$ Department of Child Health, School of Medical Sciences, KNUST, Kumasi, Ghana

Email: *ljj.gowans@gmail.com

How to cite this paper: Gowans, L.J.J., Obiri-Yeboah, S., Oti, A.A., Arthur, F.K.N., Twumasi, P., Agbenorku, P., Plange-Rhule, G. and Donkor, P. (2018) Non-Random Distribution of Human Orofacial Clefts in Ghana: Gene-Environment Interactions. Open Journal of Stomatology, 8, 35-52. https://doi.org/10.4236/ojst.2018.82004

Received: November 7, 2017

Accepted: February 6, 2018

Published: February 9, 2018

Copyright $\odot 2018$ by authors and Scientific Research Publishing Inc. This work is licensed under the Creative Commons Attribution International License (CC BY 4.0).

http://creativecommons.org/licenses/by/4.0/

\begin{abstract}
Human orofacial clefts (OFCs) are congenital anomalies that result from the breakdown of normal mechanisms that regulate the formation of the human face. They could be syndromic or non-syndromic, with a global incidence of 1:700 per live births. Environmental and genetic factors are thought to play various roles in the aetiology of OFCs. This study seeks to establish the diversity, distribution and pattern of inheritance of OFCs as well as environmental and other risk factors associated with OFCs in a Ghanaian population. A family-based, descriptive cross-sectional study that employed an interview-based survey questionnaire was used to obtain information from 467 families with history of OFCs. We employed chi-square statistics to analyse the data and used graphs to interpret the data. All previously reported subphenotypes of OFCs were observed by the present study. Clinically, about $12 \%$ of clefts in the study population were syndromic. The most common syndromic forms observed were Pierre Robin Sequence, cleft-with-club foot abnormalities and Van der Woude Syndrome. Only about 5\% of clefts in the study cohort were familial. The study also established that lower level of education of parents, poverty, late antenatal care and dietary folate deficiency are major environmental factors associated with clefts in the Ghanaian population. In conclusion, OFCs are non-randomly distributed in Ghana and folate deficiency could likely be a source of genetic mutations and "epimutations" that cause OFCs, since folate is essential for DNA methylation, replication and repair as well as histone modification.
\end{abstract}




\section{Keywords}

Orofacial Clefts (OFCs), Folate Deficiency, Low Socio-Economic Status, Non-Random Distribution, Pattern of Inheritance

\section{Introduction}

Human orofacial clefts (OFCs) are congenital malformations of oral and facial structures. Cleft lip only (CL), isolated cleft palate (CP) and cleft lip with palate (CLP) are the most common forms of OFCs. These may be syndromic or non-syndromic, with the syndromic forms presenting with additional congenital anomalies [1]. Collectively, OFCs are among the most common birth defects with a global incidence of 1 per 700 live births [2]. Race, ethnicity, geographical locations, environmental factors and socio-economic status influence the distribution of OFCs [3]. Asians have the highest incidence of OFCs, followed by Europeans, with populations of African ancestry having the lowest incidence [2]. The incidence of OFCs also differs by gender and laterality. A ratio of 2:1 male to female has been observed for $\mathrm{CL}$ whereas a ratio of 1:2 male to female has been reported for CP. In terms of laterality, a ratio of 2:1 left-sided to right-sided clefts has been observed among unilateral clefts [1].

In Ghana, there is no reliable national OFCs incidence data, due to the absence of a national birth defects registry leading to inefficient methods of reporting clefts and natality in general. In a review of hospital data from 1999 to 2005 at Komfo Anokye Teaching Hospital (KATH), Ghana, it was observed that the number of reported cases increased every year, probably due to community awareness and provision of free surgeries [4]. Subsequent review of medical records of patients with OFC in the same hospital from 2006 to 2009 revealed a yearly increase in the number of reported cases [5]. In a community-based study at $\mathrm{Wu}$ doaba cluster of villages in Ketu South District of Volta Region of Ghana, OFC prevalence was ascertained to be as high as 6.3 per 1000 people [6]. However, the incidence of OFCs may vary among various regions or ethnicities in Ghana. In a descriptive prospective survey of eleven selected health facilities in Kumasi, an incidence of 1.31 per 1000 live births was observed [7].

The various subdivisions of clefts are even more heterogeneous. OFCs may manifest as cleft lip only (CL), isolated cleft palate (CP), cleft lip and palate (CLP), submucous cleft palate (SMCP), tessier, macrostomia, or microform cleft. Many lines of evidence currently presuppose that the phenotypic spectrum or expressivity of OFCs is more complex than earlier thought. These include an array of subclinical phenotypic features observed in either an OFC patient or "unaffected" relatives [8]. Subclinical phenotypes may include minor structural variants, such as lip pits or prints [9], dental anomalies [10], abnormalities of the orbicularis oris muscles, three-dimensional facial image measurement [8] and brain variants as revealed by magnetic resonance imaging (MRI) or surrogate measures [11]. 
Palatal subphenotypes may include bifid uvula, congenital absence of uvula, and distinction of the clefts of the soft and hard palates [1].

Folate is crucial for epigenetic regulation and reprogramming during mammalian development. DNA synthesis, repair and methylation as well as histone methylation, are some of the biochemical cellular processes that rely on folate as a 1-carbon source. DNA methylation stabilizes the genome by recognizing and inactivating parasitic viral DNA sequences that infiltrate the genome. It is also crucial for transcriptional regulation, X-chromosome inactivation, parent of origin genomic imprinting and tissue-specific gene expression [12]. Methylation patterns are passed on during cell division; this is influenced by availability of folate [13] [14]. Folate levels therefore influence the occurrence of birth defects in mice [15] and humans [16] [17].

The aim of this study was to ascertain environmental and other risk factors that influence the occurrence and distribution of human OFCs in a Ghanaian population. This study also examined the phenotypic diversity as well as pattern of inheritance of OFCs in the study population through the use of interview-based survey questionnaire.

\section{Methods}

\subsection{Sampling of Subjects}

This research was approved by the local institutional review board (IRB) in the College of Health Sciences, Kwame Nkrumah University of Science and Technology (KNUST), Ghana, with the approval reference number being CHRPE/AP/217/13. To conform to internationally accepted ethical requirements, we acquired written informed consent from all participating families before data were collected from them. Probands who were at least 18 years old gave their own informed consent; however, for those who were less than 18 years, informed consent was signed by a guardian or parent.

An average of 208 patients with OFCs is encountered yearly by the Cleft Team of KATH. Majority (about 75\%) of these patients report to KATH while others are encountered during the various missionary outreaches to other political regions of Ghana by the Cleft Team of KATH (Medical Records of Cleft Clinic, KATH, 14/10/2012). Based on this, at least 135 case families were recruited yearly. The sample size was calculated using an online sample size calculator at http://www.surveysystem.com/sscalc.htm. The sample size was calculated at a confidence level of $95 \%$ and a confidence interval of 5. A total of 467 families with history of clefts participated. Because of the geographical location and missionary outreach programmes of KATH Cleft Clinic, the 135 families with history of clefts that were studied yearly likely represented almost all regions and a significant number of ethnic groups in Ghana. Case families were selected consecutively from October 2012 to December 2014. Hospital records of patients gave additional information on phenotypes and environmental exposures for participating families. For some case families, a visit was paid to communities in which 
they lived in order to collect additional samples, genetic and environmental information about them. The age range of probands was 1 week to 75 years. However, for the few probands (about $5 \%$ of 467 families) who were above 18 years as well as those whose mothers were not available or could not recall peri-conception exposures, no environmental data was collected from such families. Written, informed consent was obtained from all participating families.

For a subject to be classified as a case proband, the subject must have any of or a combination of the following congenital cleft subphenotypes: CP, CL, CLP, facial clefts, SMCP, and subclinical cleft phenotypes, such as microform cleft. A case proband was classified as having syndromic cleft whenever any other clinical, congenital, phenotypic malformations, such as club foot, presented with cleft. Also, proband was classified as having non-syndromic cleft if no clinical, congenital, phenotypic abnormalities occurred together with cleft [1] [4] [5].

\subsection{Questionnaire Administration}

A questionnaire was administered to case families. After identification of case families, any congenital abnormalities, apart from clefts, if they occurred, were noted. All generations of each case pedigree was carefully examined for any congenital defects. Moreover, since phenotype is an outcome of the interplay between genetics and environment, the questionnaire also probed into environmental exposures and some medical histories of these families. Since the uterine environment of mothers greatly influences the development of foetus [1], these exposures were ascertained primarily from the mother. For almost all these risk factors, the mothers were asked a "yes or no" question as to whether they got exposed to any of them, particularly during peri-conception three months before and three months after conception.

Daily and weekly dietary folate intake was assessed based on the consumption of fruits (such as citrus fruits and juices), slightly cooked or uncooked dark green leafy vegetables (such as lettuce), dried beans and legumes (peas), and other folate-fortified foods (such as cereals, flours, etc.). Folate is a water-soluble vitamin $B$ that is not stored in fat tissues of the body and excess folate is secreted through urine. Because of this, poor dietary folate, for even few weeks, could drastically reduce blood folate levels. It is therefore recommended that a woman who is pregnant or aspiring to do so must take at least 400 micrograms (mcg) of folic acid supplement daily in order to reduce the occurrence of birth defects (http://www.nlm.nih.gov/medlineplus/ency/article/000354.htm, 09/07/2015). Corollary to these observations, a mother that did not consume folate-rich foods daily was classified as having "dietary folate deficiency". Folate supplementation was also ascertained: daily consumption of folate-fortified foods and peri-conception intake of folic acid supplements were inquired from mothers.

Other risk factors collected included socio-economic status, level of education and period when mothers accessed antenatal care. Socio-economic status was assessed based on the occupation of both mother and father. Families with reliable 
source of monthly income (at least GH\$500 - about US\$130), such as teachers, were classified as "high income earners". "Low income earners" refer to people with no reliable source of monthly income (less than GH\$500), such as the unemployed, peasant farmers, artisans, etc.

(http://www.statsghana.gov.gh/docfiles/glss6/GLSS6_Main\%20Report.pdf).

Time of antenatal care attendance was also ascertained based on the time lapse after conception before mother visited hospital. This is mainly the time that folate or multivitamin supplementation was initiated.

\subsection{Statistical Analyses}

Chi-square and $p$-values were calculated using In Silico Project Support for Life Sciences (http://in-silico.net/tools/statistics/chi2test). All charts were drawn with Excel and error bars indicated are standard errors.

\section{Results}

\subsection{Pattern of Inheritance, Phenotypic Diversity and Distribution of Clefts}

A total of 467 case pedigrees were recruited. The case pedigrees consisted of 413 (88\%) non-syndromic OFC (NSOFC) case pedigrees and 54 (12\%) syndromic case pedigrees. About $5 \%(n=24)$ of the case pedigrees were multiplex families whiles the remaining pedigrees were simplex families. In 10 out of the 24 multiplex families, clefts occurred only in the nuclear family whereas in the remaining multiplex families, clefts occurred in other extended family members. Figure 1 shows three case pedigrees: GH20134972 and GH20130786 are multiplex pedigrees whereas GH20140578 is a simplex pedigree.

Diverse cleft phenotypes were observed in the study population (Table 1; Figures 2-4). These classifications were based on affected part of the face, the severity of the cleft as well as the laterality. There was significant difference ( $p=$ $0.0073)$ between the number of males $(n=213)$ and females $(n=254)$ affected with clefts in the study population, with higher number of females being affected. This effect emanated from the 1:2 ratio of males $(n=43)$ to females $(n=$ 83) affected with CP $(p<0.0001)$, since there was no significant difference between number of males and females affected with CL $(p=0.5865)$, CLP ( $p=$ $0.4996)$ and special clefts $(p=0.9999)$. There was also significant difference in laterality for CL $(p<0.0001)$ as well as CLP $(p=0.0119)$, with left unilateral clefts being more common.

Many syndromic forms of clefts were observed in the study population (Table 2 ). These classifications were based only on clinical but not molecular evidence. Syndromes were assigned to some probands based on clinical evidence whereas for some probands, only phenotypes or symptoms were described since it was difficult assigning a particular syndrome to such probands based on clinical records and were just classified as having multiple congenital anomalies (MCAs). Nine cases of Pierre Robin Sequence (PRS) were observed, making it the most common 


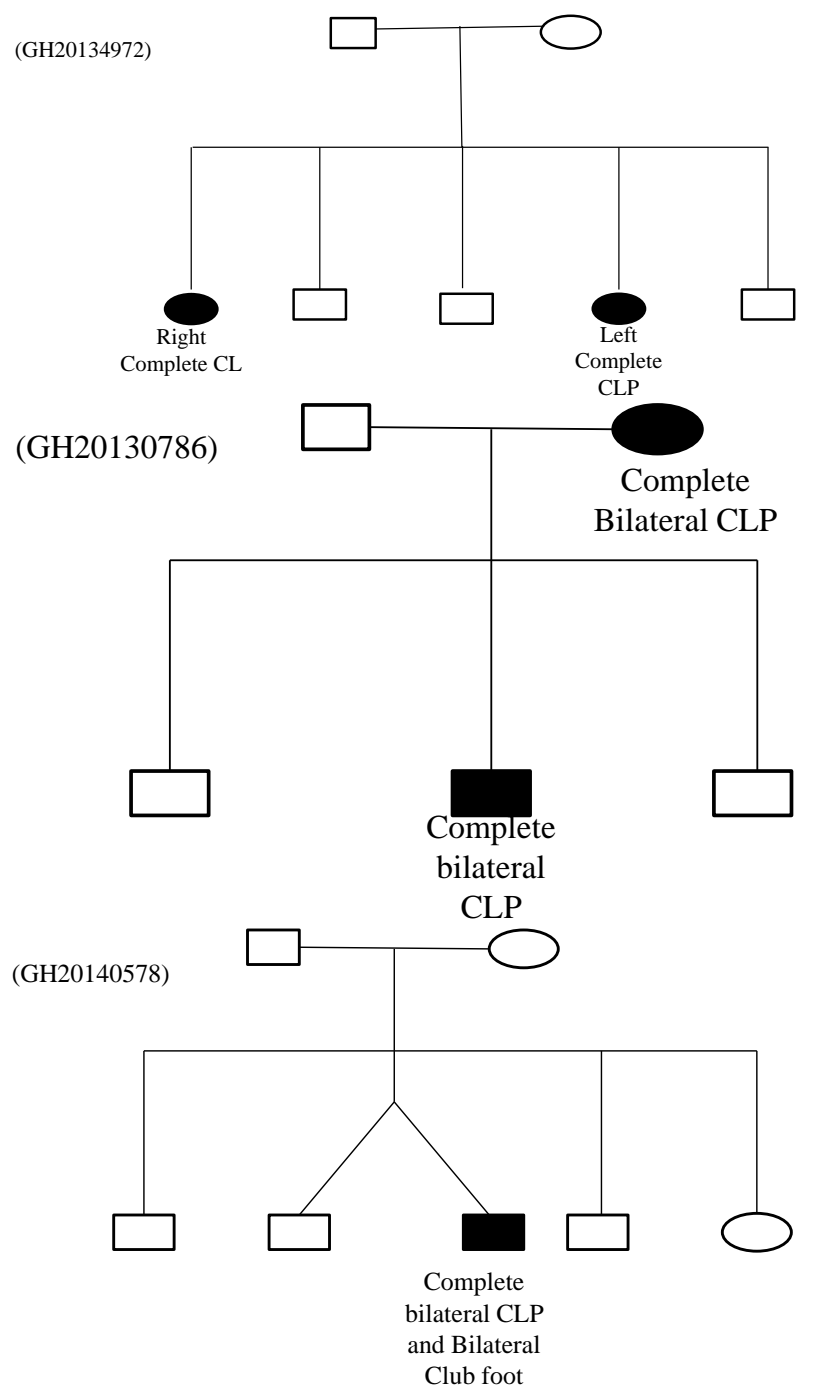

Figure 1. Multiplex and simplex case pedigrees observed in the study cohort.

(16.67\%) syndromic form. However, it was difficult to classify these cases as a single syndrome, since there could be more than one underlying syndrome, such as Stickler and Treacher Collins Syndromes, causing PRS (http://www.omim.org). The most well-characterized and common, syndromic form of OFCs observed was Van der Woude Syndrome (VWS). Diagnosis of VWS was based on the presence of OFCs together with lip pits, being bilateral or unilateral lip pits. Clefts that presented with only club foot were the most common MCA subphenotype; 6 of such MCAs were observed. Other MCAs presented with a spectrum of abnormalities that included overt OFCs, hexadactyly, microphthalmia, anophthalmia, ankyloglossia, penoscrotal webbing, undescended testes, hypospadias, ocular hypertelorism, wide low-set ears, etc.

Case families were also characterized by low socio-economic status and parents that were within the actively-reproducing or youthful age. About $66 \%$ of families lived in rural areas whereas the remaining 34\% lived in urban areas. Even for urban dwellers, most families lived in slums and other low-standard 


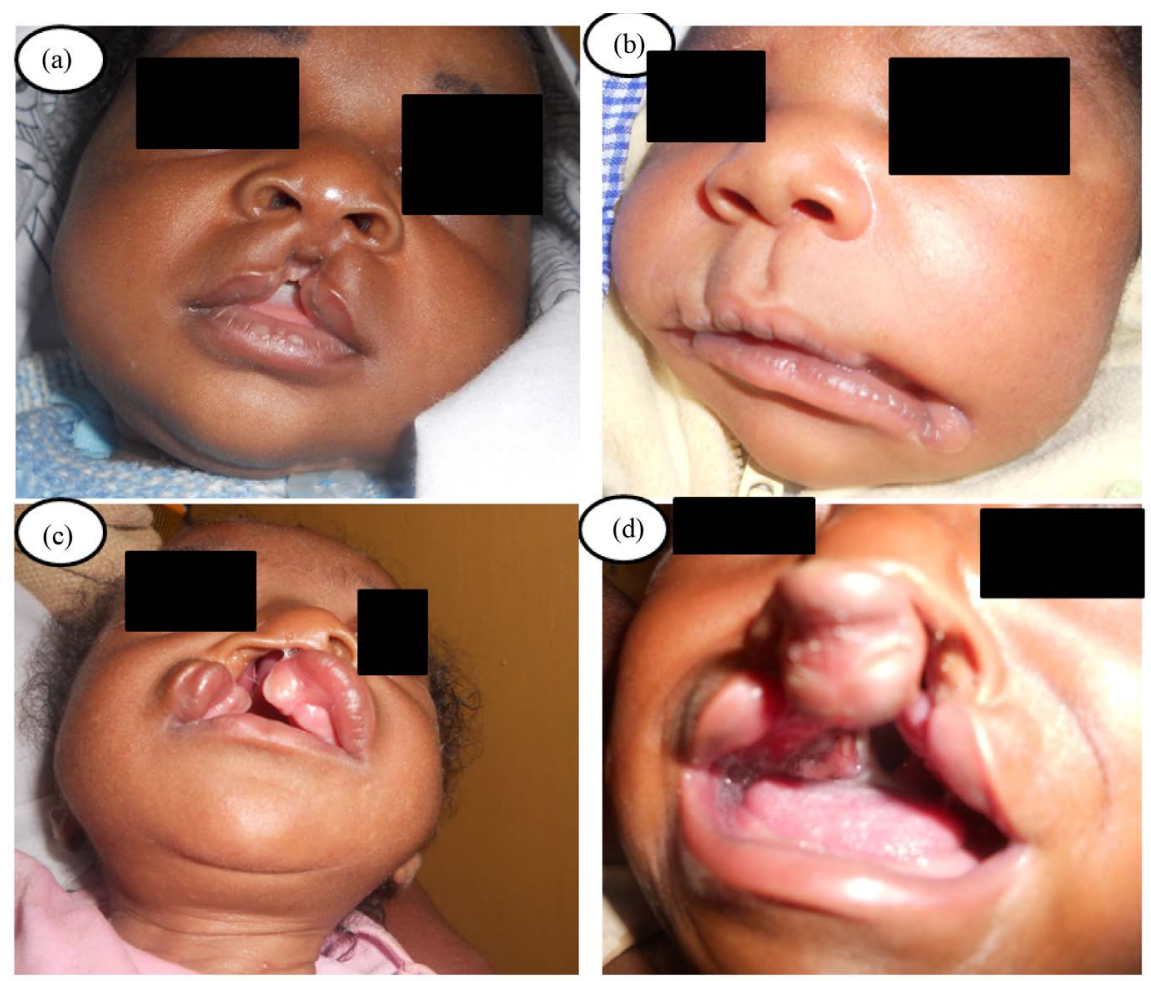

Figure 2. Phenotypic diversity of NSOFCs. (a) Incomplete midline CL; (b) Bilateral macrostomia; (c) Right complete unilateral CLP; (d) Complete bilateral CLP.

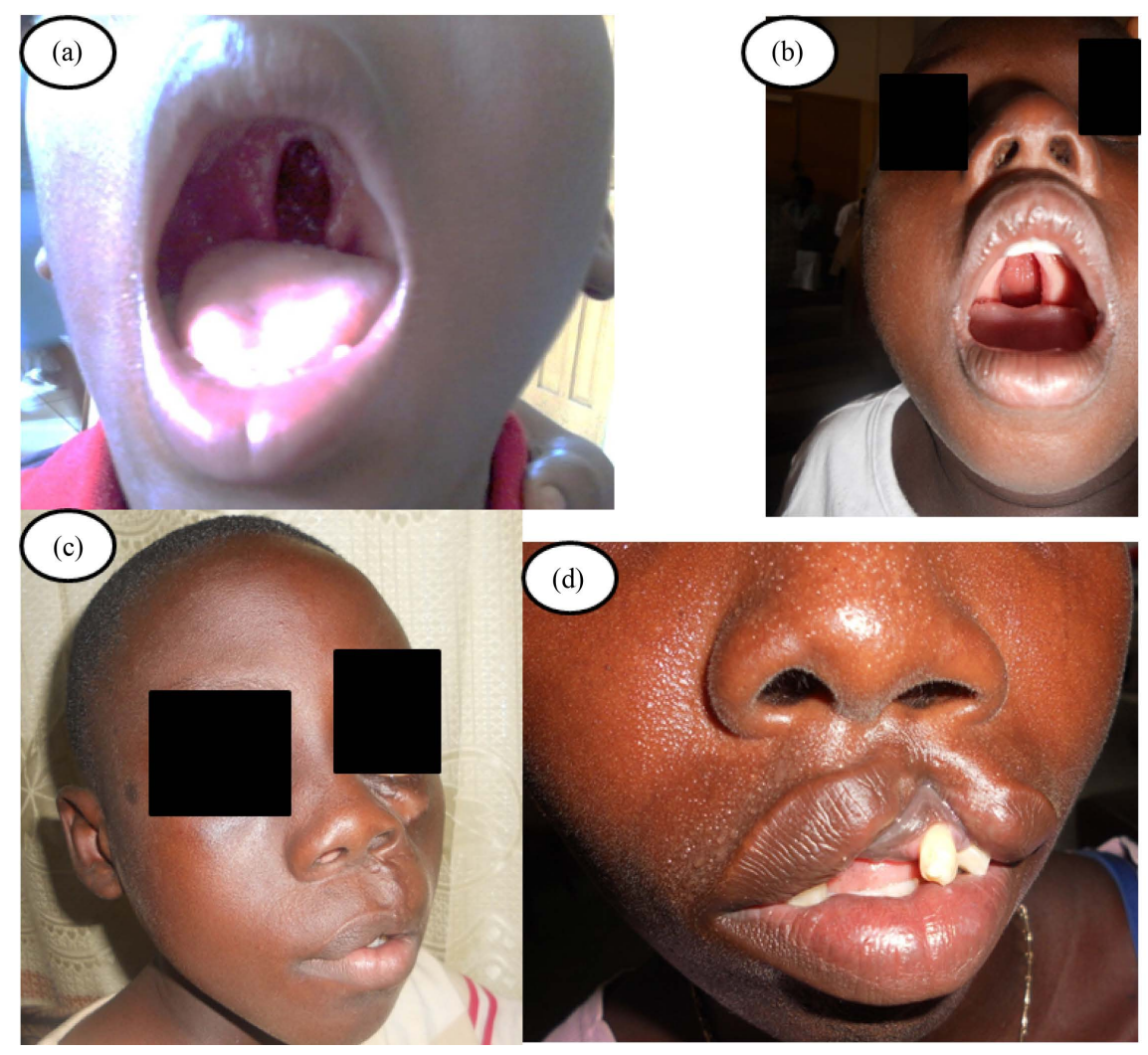

Figure 3. Further phenotypic diversity of NSOFCs. (a) SMCP; (b) Wide complete CP; (c) Repaired left facial cleft and CLP; (d) Left complete CL. 


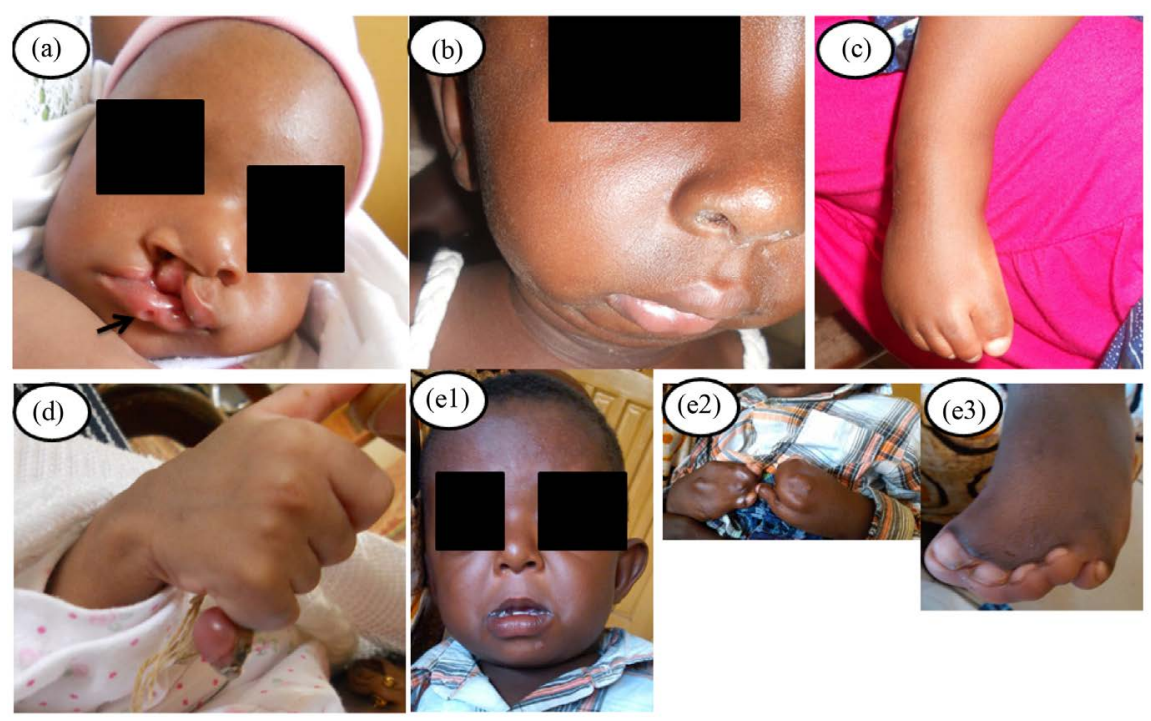

Figure 4. Syndromic clefts. (a) A VWS patient with bilateral lip pits (arrows); (b) A patient with Pierre Robin Sequence, characterized by micrognathia, CP and glossoptosis; (c) A patient with OFC who also presented with club foot; (d) A patient with OFC who also presented with hexadactyly; (e) A patient with Apert Syndrome who presented with (e1) low-set ears and characteristic facial appearance, (e2) Syndactyly of fingers and (e3) Syndactyly of toes.

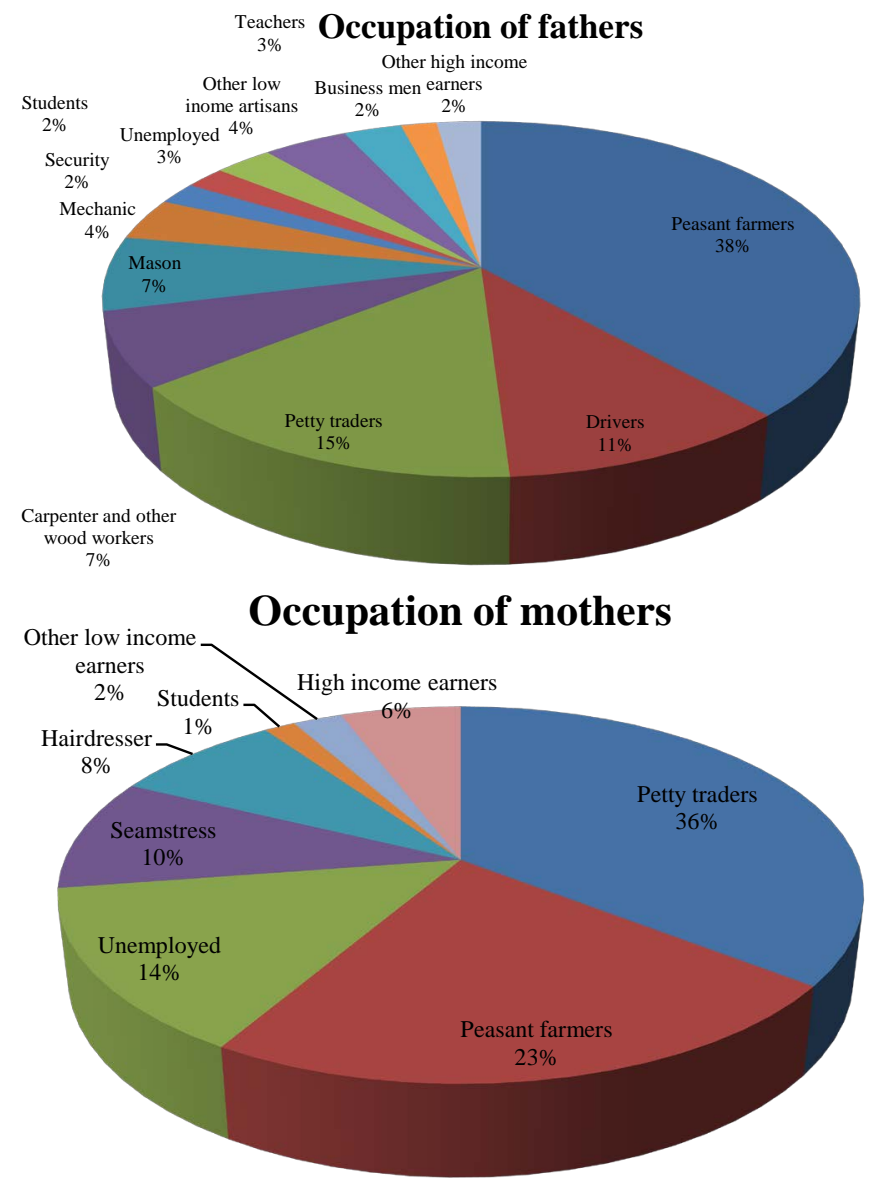

Figure 5. Occupation or economic status of case families. 
Table 1. Diversity of orofacial clefts classified based on severity and laterality.

\begin{tabular}{|c|c|c|c|c|c|c|c|c|}
\hline \multirow{2}{*}{ Type of cleft } & \multicolumn{3}{|c|}{ Non-syndromic clefts } & \multicolumn{3}{|c|}{ Syndromic clefts } & \multirow[b]{2}{*}{$\begin{array}{l}\text { Total } \\
A+B\end{array}$} & \multirow{2}{*}{$\begin{array}{l}\text { Subphenotype } \\
\text { (Total A + B) } \\
\text { as a percentage } \\
\text { of total clefts }\end{array}$} \\
\hline & Male & Female & Total A & Male & Female & Total B & & \\
\hline \multicolumn{9}{|c|}{ Cleft Lip only (CL) } \\
\hline Right Unilateral CL & 20 & 23 & 43 & 5 & 0 & 5 & 48 & $10.28 \%$ \\
\hline Left Unilateral CL & 46 & 44 & 90 & 2 & 1 & 3 & 93 & $19.91 \%$ \\
\hline Bilateral CL & 7 & 8 & 15 & 1 & 0 & 1 & 16 & $3.43 \%$ \\
\hline Midline CL & 1 & 1 & 2 & 0 & 1 & 1 & 3 & $0.64 \%$ \\
\hline Macrostomia & 5 & 4 & 9 & 0 & 0 & 0 & 9 & $1.92 \%$ \\
\hline Totals of CL & 79 & 80 & 159 & 8 & 2 & 10 & 169 & $36.19 \%$ \\
\hline \multicolumn{9}{|c|}{ Isolated Cleft Palate (CP) } \\
\hline Isolated CP & 21 & 60 & 81 & 8 & 13 & 21 & 102 & $21.84 \%$ \\
\hline $\begin{array}{l}\text { Submucous CP } \\
(\mathrm{CP}+\text { Bifiduvula })\end{array}$ & 13 & 8 & 21 & 1 & 2 & 3 & 24 & $5.14 \%$ \\
\hline Totals of CP & 34 & 68 & 102 & 9 & 15 & 24 & 126 & $26.98 \%$ \\
\hline \multicolumn{9}{|c|}{ Cleft Lip and Palate (CLP) } \\
\hline Right CLP & 22 & 17 & 39 & 2 & 0 & 2 & 41 & $8.78 \%$ \\
\hline Left CLP & 31 & 30 & 61 & 0 & 1 & 1 & 62 & $13.28 \%$ \\
\hline Bilateral CLP & 14 & 28 & 42 & 6 & 6 & 12 & 54 & $11.56 \%$ \\
\hline Midline CLP & 1 & 0 & 1 & 0 & 0 & 0 & 1 & $0.21 \%$ \\
\hline Totals of CLP & 68 & 75 & 143 & 8 & 7 & 15 & 158 & $33.83 \%$ \\
\hline \multicolumn{9}{|c|}{ Special Clefts } \\
\hline Oblique Facial Clefts & 3 & 1 & 4 & 1 & 1 & 2 & 6 & $1.28 \%$ \\
\hline $\begin{array}{r}\text { Ankyloglossia } \\
\text { (Tongue-Tie) }\end{array}$ & 1 & 0 & 1 & 0 & 1 & 1 & 2 & $0.43 \%$ \\
\hline Midline Lower Lip CL & 0 & 1 & 1 & 0 & 0 & 0 & 1 & $0.21 \%$ \\
\hline Microform Clefts & 1 & 2 & 3 & 1 & 1 & 2 & 5 & $1.07 \%$ \\
\hline Totals & 5 & 4 & 9 & 2 & 3 & 5 & 14 & $3.00 \%$ \\
\hline
\end{tabular}

areas. Moreover, OFCs appeared to be endemic at specific locations: Manso and Asante Akyem Agogo, Begoro, Sefwi and Dunkwa-On-Off in areas of Ashanti, Eastern, Western and Central Regions, respectively. Majority of mothers (90\%) and fathers (75\%) never went to school or ended their education at the elementary level (Figure S1). Most of these parents could neither read nor write. Since illiteracy level in Ghana is 26\% (2010 Population and Housing Census, Ghana), illiteracy was significantly $(p<0.0001)$ associated with families with clefts. About $15 \%$ and $5 \%$ of fathers and mothers, respectively, ended their education at Senior High School; $10 \%$ and 5\% of fathers and mothers, respectively, have had tertiary education. Furthermore, about $87 \%$ of mothers and $70 \%$ of fathers gave birth to the probands when they were within the age range of 21 to 40 years 
Table 2. Syndromic forms of OFCs in the study population.

\begin{tabular}{|c|c|c|c|c|}
\hline Name of syndrome & Males & Females & Total & $\begin{array}{c}\text { A syndromic form as a } \\
\text { percentage of total number } \\
\text { syndromic forms }\end{array}$ \\
\hline $\begin{array}{l}\text { Van der Woude Syndrome } \\
\text { (VWS) }\end{array}$ & 4 & 2 & 6 & $11.11 \%$ \\
\hline Mobius Syndrome & 1 & 1 & 2 & $3.70 \%$ \\
\hline DiGeorge Syndrome & 1 & 0 & 1 & $1.85 \%$ \\
\hline Pierre Robin Sequence (PRS) & 2 & 7 & 9 & $16.67 \%$ \\
\hline Fragile-X Syndrome & 0 & 1 & 1 & $1.85 \%$ \\
\hline Edward Syndrome & 1 & 0 & 1 & $1.85 \%$ \\
\hline Opitz Syndrome & 1 & 0 & 1 & $1.85 \%$ \\
\hline Goldenhar Syndrome & 2 & 3 & 5 & $9.26 \%$ \\
\hline Apert Syndrome & 1 & 0 & 1 & $1.85 \%$ \\
\hline Stickler Syndrome & 0 & 1 & 1 & $1.85 \%$ \\
\hline Cri du Chat Syndrome & 0 & 1 & 1 & $1.85 \%$ \\
\hline Amniotic Band Syndrome & 0 & 1 & 1 & $1.85 \%$ \\
\hline Kabuki Syndrome & 1 & 0 & 1 & $1.85 \%$ \\
\hline Holoprosencephaly & 1 & 0 & 1 & $1.85 \%$ \\
\hline Cleft-club foot only & 5 & 1 & 6 & $11.11 \%$ \\
\hline $\begin{array}{l}\text { Other multiple congenital } \\
\text { anomalies (MCAs) }\end{array}$ & 7 & 9 & 16 & $29.62 \%$ \\
\hline Total & 27 & 27 & 54 & \\
\hline
\end{tabular}

(Figure S2). Thus, clefts patients were mostly born to actively, youthful, reproducing parents; therefore, advanced age-related gross chromosomal abnormalities may largely not be responsible for cleft aetiology. About $95 \%$ of both mothers and fathers were low income earners (Figure 5). Only about $5 \%$ of families with clefts had reliable source of income of at least US $\$ 130$ per month. High income earners included a doctor, teachers, civil servants, public service workers, as well as traders who owned permanent stores and were making reliable sales every month. Therefore, OFCs occurred in all regions of Ghana, though clefts were endemic at certain rural settings of various regions where poverty and lower level of education were high.

\subsection{Environmental and Other Risk Factors}

Some mothers in case families were exposed to diverse risk factors (Figure 6). A very significant $(p<0.0001)$ percentage (over $90 \%)$ of mothers had poor dietary folate intake; these mothers did not consume folate-rich foods for at least three times a week. Most mothers considered eating of folate-rich foods as the privilege of the rich. Moreover, about $90 \%$ of mothers hardly ate any folate-fortified food, such as fortified cereals. Furthermore, only about $14 \%$ of mothers had folate supplementation within the first trimester whereas about $70 \%$ of mothers 
took folic acid supplements after the first trimester. About $16 \%$ of mothers never took any folate supplements during gestation. In all families, folate supplementation was initiated during the first visit to antenatal clinic. Over $85 \%$ of mothers either accessed antenatal care after 3 months of gestation or did not access antenatal care at all (Figure 7).

Enema usage was also common among some mothers, with about $30 \%$ of mothers using enemas during conception (Figure 6). Also worthy of note is the high number of mothers (about $30 \%$ ) that were consistently exposed to smoke from sources such as firewood, refuse dumps, factories, etc. Some medical history of mothers (such as miscarriage, still births, consanguinity, family planning and lack of antenatal care) were observed in less than $20 \%$ of mothers, suggesting these factors may not be major risk factors associated with OFCs.

\section{Discussions}

OFCs may be common in Ghana. Recent advances in cleft care in Ghana have resulted in higher number of reported cases [4] [5]. Though no reliable national incidence is known, population-based and hospital-based epidemiological studies suggest OFCs may be prevalent congenital abnormalities in Ghana. In a population-based study at Wudoaba cluster of villages, a prevalence of as high as 6.3 per 1000 people was recorded [6]. However, in a hospital-based study in

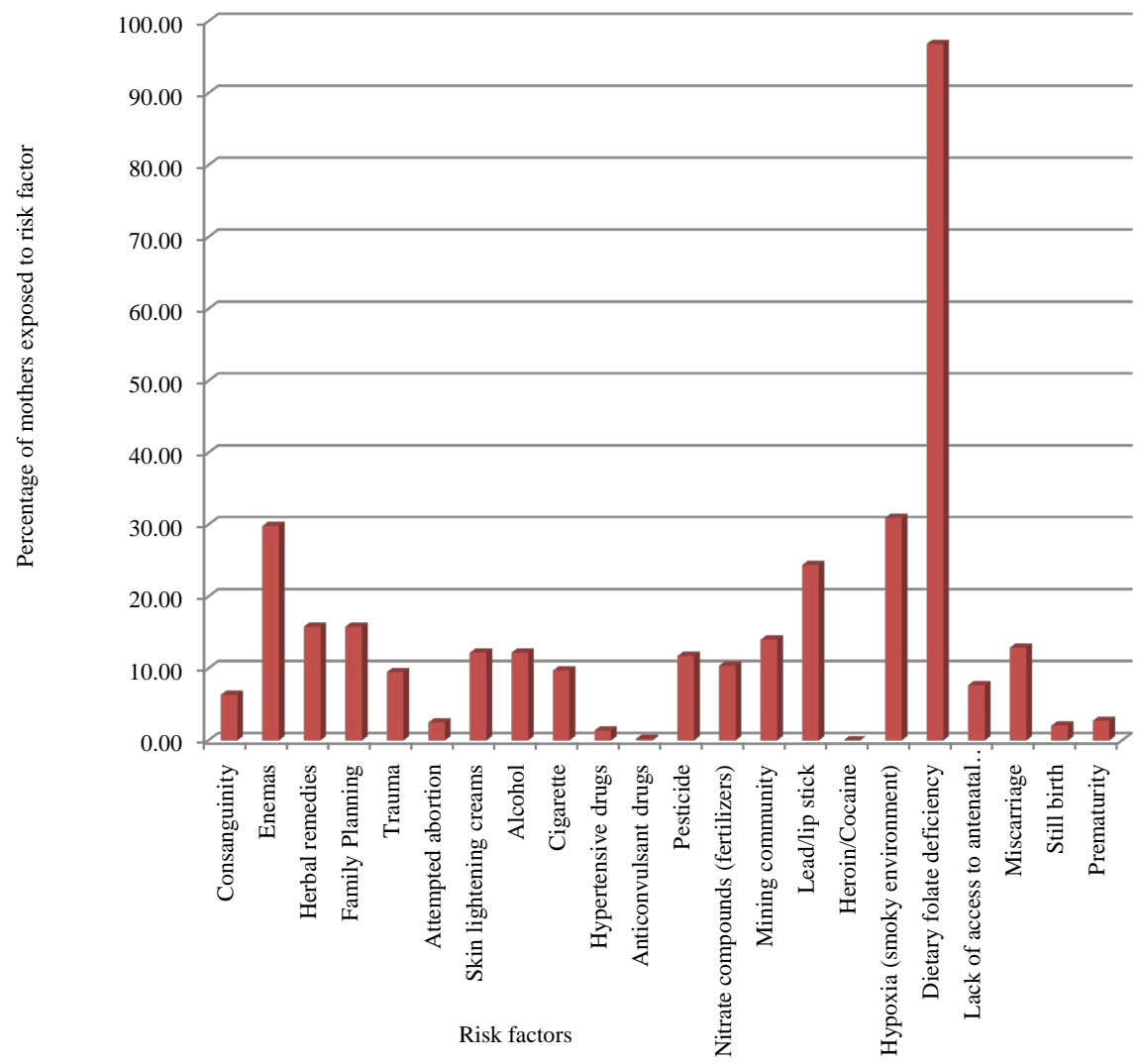

Figure 6. Maternal exposure to risk factors that include environmental exposures and some medical history. 


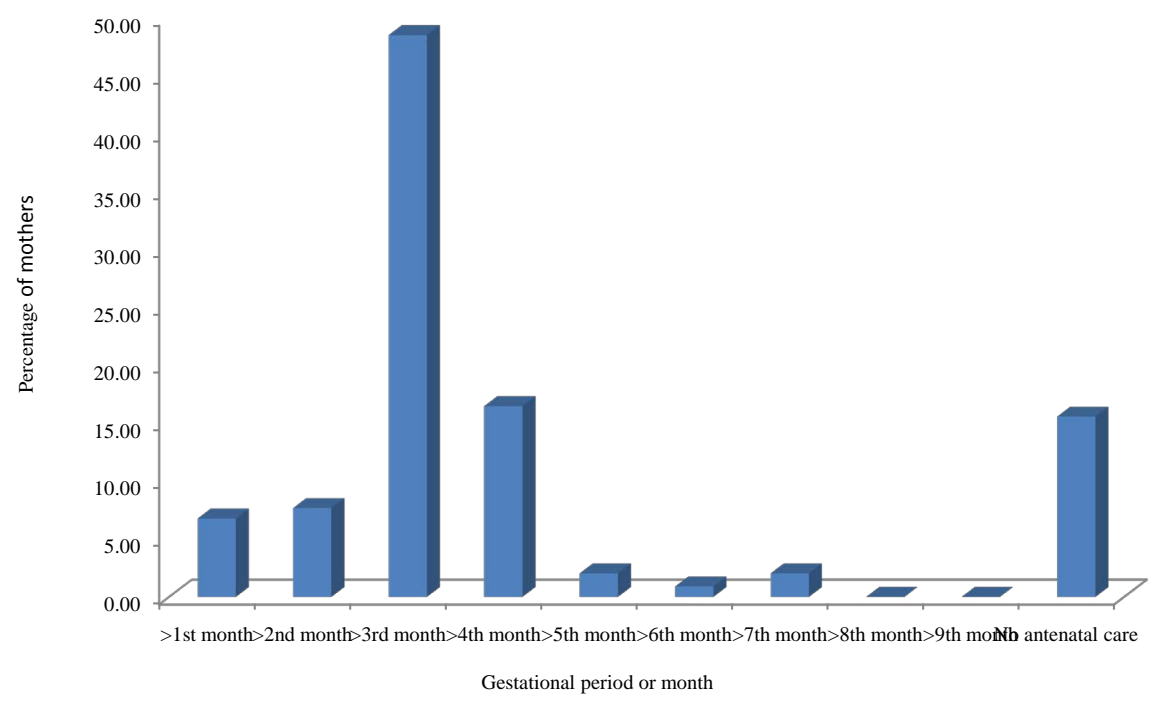

Figure 7. Number of months after conception after which mother got antenatal care. The time of first antenatal care is usually when folate supplementation is started. It was observed that over $80 \%$ of mothers either had folate supplementation after three months of gestation or had no folate supplementation at all. > implies after the indicated month.

Kumasi, a low incidence rate of 1.37 per 1000 live births was observed [7]. Though the present study did not attempt to determine incidence of OFCs, it was interestingly observed that clefts were endemic at certain parts of Ghana. For example, many cases were reported from Manso, Asante Akyem Agogo, Begoro and Sefwi areas. This observation suggests non-random distribution of clefts in Ghana, buttressing the assertion that geographical locations and environmental risk factors influence the incidence of OFCs [3].

OFC phenotypes in Ghana are as diverse as have been reported elsewhere [1]. No significant differences were observed in the subphenotypes of CL, CP and CLP, though earlier studies suggest $\mathrm{CP}$ is a less common subphenotype [4] [5]. Furthermore, there was significant difference between the number of males and females affected with clefts, with higher number of females being affected. This observation is corroborated by a recent study in Kumasi that encompassed 11 hospitals [7]. The higher incidence of clefts in females emanated mainly from the about 1:2 males to females affected with $\mathrm{CP}$ in the study cohort; this $\mathrm{CP}$ observation is consistent with most literature [1] [18], though not all [7]. Earlier studies in KATH suggested the contrary: males were more affected with clefts than females [4] [5]. Also, no significant differences were observed between males and females affected with CL and CLP. This observation is contrary to literature, which suggests a 2:1 male to female ratio for these subphenotypes [1]. In harmony with reports elsewhere [1], left unilateral clefts were as twice more common than right unilateral clefts in the present study. In a Nigeria study, it was also observed that left unilateral clefts were more common than right unilateral clefts, though more males were observed in the study cohort [18].

Most cleft cases in Ghana were non-familial and had complex pattern of genetic inheritance. Only about $5 \%$ of case pedigrees were multiplex families. Inte- 
restingly, even within these multiplex families, no clear pattern of genetic inheritance was observed. For example, in pedigree GH20134972, all females in that nuclear family are affected whereas no parent or male sibling is affected. Even within this pedigree, clefts differed in severity and laterality. Also, in pedigree GH20130786, a mother with complete bilateral CLP transmits the exact phenotype to a male child while all other male siblings remain unaffected. For this particular pedigree, future generations must be studied before a conclusive pattern of inheritance can be obtained. Observations from these two pedigrees suggest to a large extent a non-Mendelian pattern of inheritance of clefts even in some familial cases and the urgent need for molecular data in pedigree analyses. About $95 \%$ of cleft cases were non-familial in that the proband is the first person to be born with cleft in these families. In the simplex pedigree GH20140578, a monozygotic twin presented with complete bilateral CLP as well as bilateral club foot, though the other twin had no congenital anomalies. This discordance in occurrence of clefts even among monozygotic twins, suggests an interaction between genetic and environmental factors in the pathogenesis of OFCs [1] [19]. This evidence from twins also suggests that sporadic, somatic mutations that emanate after fertilization and embryo cleavage may sometimes account for cleft aetiology [20] [21]. Thus, genetic mosaicism may be common among cleft patients. Corollary to these observations, a multifactorial pattern of inheritance may account for cleft occurrence in the Ghanaian population [1] [19].

The multifactorial pattern of inheritance proposed here is based on a number of observations made by this study that have also been reported elsewhere [22]. Firstly, most affected children (about 95\%) had normal parents. Secondly, the recurrence risk increased with the number of affected individuals in the family. For example, in 10 multiplex families where clefts occurred within the nuclear family, $70 \%$ of these clefts were transferred from parents to probands whereas only $30 \%$ were clefts that occurred among siblings. In 5 out of 7 cases of parent to proband transmission, cleft was transferred from affected mothers to affected daughters. In one case, the exact phenotype of complete bilateral CLP was transferred from a mother to a male child whereas in the last pedigree, CL was transferred from a father to a female child. Interestingly, the exact cleft subphenotypes in parents were transferred to the probands: 2 complete CLP, 4 complete $\mathrm{CL}$ as well as 1 complete $\mathrm{CP}$ were transmitted from parents to offspring. Thus, $\mathrm{CP}$ and $\mathrm{CL} / \mathrm{P}$, which are embryologically as well as aetiologically distinct [1], did not segregate together in a family. Thirdly, recurrence risk increased with the severity of the abnormality: all 10 nuclear multiplex families observed in the present study had severe subphenotypes of clefts. These included complete CLP, CL and CP. Lastly, consanguinity slightly raised the recurrence risk of an affected family: familial clefts were more common in parts of the Northern and Volta [6] Regions where consanguinity was high.

Clinically, the vast majority of clefts in Ghana were non-syndromic. About 88\% of case pedigrees were non-syndromic whereas only $12 \%$ were syndromic. This observation is statistically in line with global cleft distribution of $70 \%$ non-syndromic 
cases and 30\% syndromic cases [1], though NSOFCs was extremely high in the present cohort. Interestingly, molecular evidence gathered by a parallel study [23] suggests that the percentage of syndromic clefts may actually be higher than was ascertained through clinical data. Our observations suggest the urgent need to combine both clinical and molecular data before making any absolute cleft diagnosis. VWS was the most well-characterized and common syndromic form of clefts in the study cohort and this also is consistent with literature [1]. Though a higher number of PRS cases were observed, it was difficult to cluster them as one syndrome since PRS has a heterogeneous genetic architecture (OMIM). Also worthy of note was the high number of cleft-club foot only phenotype, $80 \%$ of which occurred in males. This male dominance suggests an X-linked trait. Moreover, $\mathrm{CP}$ was observed more in syndromic pedigrees than other cleft subphenotypes.

Most case families were characterized by low socio-economic status and youthful parents. About $80 \%$ of case parents never went to school and therefore could neither read nor write; therefore, illiteracy was significantly $(p<0.0001)$ associated with families with clefts. Moreover, over $90 \%$ of parents were low income earners, as a result of lack of employment or were in occupations with low income. These observations are in harmony with those made elsewhere [3] that suggest that clefts distribution is influenced by socio-economic status. Lastly, clefts were mostly observed in families with parent within the age range of 21 to 45 years. Gross chromosomal abnormalities-related genetic defects are very predominant in children born to old-aged parents. Since most parents observed in the present study were youthful, old age-associated chromosomal defects may not significantly account for cleft occurrence in the Ghanaian population.

The most striking risk factor in cleft families was folate deficiency. Over 95\% of mothers had poor dietary folate intake whereas about $86 \%$ of mothers either took folic acid supplements after the first trimester or had no folate supplements at all; this is complicated by lack of or delayed antenatal care. Folate is crucial for DNA methylation, repair and synthesis as well as histone modifications [12]. These processes are overly crucial during embryogenesis and gametogenesis: except few imprinted genes, DNA methylation patterns are globally erased very early in these processes and are reprogrammed later in development. This window of ontogeny gives room for environmental influences: lack of folate, which provides a one-carbon source for DNA methylation, may alter methylation patterns [13] [14]. For example, folate levels influence methylation patterns of agouti mouse, inadvertently leading to birth defects [15]. This may lead to "epimutations", with attendant dysregulation of genes. Since DNA methylation also stabilizes the genome, alterations in methylation patterns could also lead to high level of mutations in genes, which are usually marked by methylated CpG islands [12] [16] [17]. All these observations suggest that folate deficiency could contribute significantly to the occurrence of genetic mutations and epimutations. Since the human face (including lip and palate) form by 10 weeks of gestation (http://www.indiana.edu/ anat550/hnanim/face/face.html, 17/01/2015), folate supplementation after the first trimester is less likely to avert clefts. 
Hypoxia and use of traditional medicine (enemas and other herbal remedies) were also common among case mothers. Low molecular oxygen levels, resulting from hypoxia, have been shown to alter the function of $P H F 8$ gene, which is a histone lysine demethylase [24]. Moreover, over 30\% of mothers used traditional medicines, which were usually crude plant concoctions. Some of these crude plants preparation have been shown to cause congenital deformities [12].

\section{Conclusion}

OFCs show multifactorial pattern of inheritance in the Ghanaian population, because both genes and environmental factors interact to initiate cleft pathogenesis. The study cohort exhibited some hallmarks of multifactorial inheritance: 95\% of cleft patients had normal parents, cleft recurrence risk was higher among multiplex families, recurrence risk increased with the severity of the abnormality and consanguinity slightly increased the recurrence risk of clefts. Environmental and other risk factors also influenced the occurrence and distribution of OFCs, with attendant non-random distribution of OFCs among the Ghanaian populace. About $90 \%$ of case families were of low socio-economic status. A significant percentage of case parents also never went to school or ended their education, at most, at the elementary level. Significant percentage (over 90\%) of case mothers had poor dietary folate deficiency, coupled with no or delayed antenatal care. Other exposures, such as hypoxia and use of traditional medicine may also play crucial roles in cleft aetiology. In conclusion, the non-random distribution of OFCs among the study population is significantly influenced by geographical locations and risk factors such as low socio-economic status, folate deficiency and delayed antenatal care. Future studies may focus on methylation patterns of DNA and histones in patients with OFCs.

\section{Limitations}

A limitation of this study is that it is hospital-based and therefore could not include families that never reported to any hospital. The sample size was also calculated based on hospital records; the lack of birth defect registry in Ghana is hampering the accurate estimation of the burden of birth defects, including orofacial clefts.

\section{Acknowledgements}

We appreciate the sacrifices of all the families that participated in this research. We are also grateful to all Doctors and Nurses at the Cleft Clinic, Komfo Anokye Teaching Hospital, Kumasi, Ghana, where sample collection was done. This work was supported by The Ghana Cleft Foundation (LJJG).

\section{Conflict of Interests}

Authors declared they have no conflict of interest. 


\section{Authors' Contribution}

LJJG, FKNA, PT and PD designed the project and made significant contributions to data collection. PD, PA, GPR, AAO and SOY carried out the diagnosis of patients. All authors made significant contributions to data analyses, manuscript writing and editing.

\section{References}

[1] Dixon, M.J., Marazita, M.L., Beaty, T.H. and Murray, J.C. (2011) Cleft Lip and Palate: Understanding Genetic and Environmental Influences. Nature Reviews Genetics, 12, 167-178. https://doi.org/10.1038/nrg2933

[2] Mossey, P.A. and Modell, B. (2012) Epidemiology of Oral Clefts 2012: An International Perspective. Frontiers of Oral Biology, 16, 1-18.

https://doi.org/10.1159/000337464

[3] Gorlin, R.J., Cohen, M.M. and Hennekam, R.C.M. (2001) Syndromes of the Neck and Head. Oxford University Press, New York.

[4] Donkor, P., Bankas, D.O., Agbenorku, P., Plange-Rhule, G. and Ansah, S.K. (2011) Cleft Lip and Palate Surgery in Kumasi, Ghana: 2001-2005. Journal of Craniofacial Surgery, 22, 532-536.

[5] Agbenorku, P., Ansah, S., Acheampong, A., Sabbah, D., Bankas, D., Adu, E., et al. (2011) Komfo Anokye Teaching Hospital Multidisciplinary Cleft Clinic. Journal of Craniofacial Surgery, 22, 532-536. https://doi.org/10.1097/SCS.0b013e318207f462

[6] Agbenorku, P., Agbenorku, M., Iddi, A., Abude, F., Sefenu, R., Matondo, P., et al. (2011) A Study of Cleft Lip/Palate in a Community in the South East of Ghana. European Journal of Plastic Surgery, 34, 267-272. https://doi.org/10.1007/s00238-010-0513-6

[7] Agbenorku, P., Yorke, M., Danso, K.A. and Turpin, C. (2013) Incidence of Orofacial Clefts in Kumasi, Ghana. ISRN Plastic Surgery, 2013, Article ID: 28903. https://doi.org/10.5402/2013/280903

[8] Weinberg, S.M., Naidoo, S.D., Bardi, K.M., Brandon, C.A., Neiswanger, K., Resick, J.M., et al. (2009) Face Shape of Unaffected Parents with Cleft Affected Offspring: Combining Three-Dimensional Surface Imaging and Geometric Morphometrics. Orthodontics \& Craniofacial Research, 12, 271-281. https://doi.org/10.1111/j.1601-6343.2009.01462.x

[9] Neiswanger, K., Walker, K., Klotz, C.M., Cooper, M.E., Bardi, K.M., Brandon, C.A., et al. (2009) Whorl Patterns on the Lower Lip Are Associated with Nonsyndromic Cleft Lip with or without Cleft Palate. American Journal of Medical Genetics Part A 149, 2673-2679. https://doi.org/10.1002/ajmg.a.33089

[10] Vieira, A.R., McHenry, T.G., Daack-Hirsch, S., Murray, J.C. and Marazita, M.L. (2008) A Genome Wide Linkage Scan for Cleft Lip and Palate and Dental Anomalies. American Journal of Medical Genetics Part A, 146, 1406-1413. https://doi.org/10.1002/ajmg.a.32295

[11] Nopoulos, P., Richman, L., Andreasen, N.C., Murray, J.C. and Schutte, B. (2007) Abnormal Brain Structure in Adults with Van der Woude Syndrome. Clinical Ge netics, 71, 511-517. https://doi.org/10.1111/j.1399-0004.2007.00799.x

[12] Crider, K.S., Yang, T.P., Berry, R.J. and Bailey, L.B. (2012) Folate and DNA Methylation: A Review of Molecular Mechanisms and the Evidence for Folate's Role. Advances in Nutrition, 3, 21-38. https://doi.org/10.3945/an.111.000992 
[13] Cravo, M., Fidalgo, P., Pereira, A.D., Gouveia-Oliveira, A., Chaves, P., Selhub, J., et al. (1994) DNA Methylation as an Intermediate Biomarker in Colorectal Cancer: Modulation by Folic Acid Supplementation. European Journal of Cancer Prevention, 3, 473-479. https://doi.org/10.1097/00008469-199411000-00004

[14] Smith, A.D., Kim, Y.I. and Refsum, H. (2008) Is Folic Acid Good for Everyone? The American Journal of Clinical Nutrition, 87, 517-533.

[15] Waterland, R.A. (2009) Early Environmental Effects on Epigenetic Regulation in Humans. Epigenetics, 4, 523-525. https://doi.org/10.4161/epi.4.8.10155

[16] Heijmans, B.T., Tobi, E.W., Stein, A.D., Putter, H., Blauw, G.J., Susser, E.S., et al. (2008) Persistent Epigenetic Differences Associated with Prenatal Exposure to Famine in Humans. Proceedings of the National Academy of Sciences, 105, 17046-17049. https://doi.org/10.1073/pnas.0806560105

[17] Tobi, E.W., Lumey, L.H., Talens, R.P., Kremer, D., Putter, H., Stein, A.D., et al. (2009) DNA Methylation Differences after Exposure to Prenatal Famine Are Common and Timing- and Sex-Specific. Human Molecular Genetics, 18, 4046-4053. https://doi.org/10.1093/hmg/ddp353

[18] Butali, A., Adeyemo, W.L., Mossey, P.A., Olasoji, H.O., Onah, I.I., Adebola, A., et al. (2014) Prevalence of Orofacial Clefts in Nigeria. Cleft Palate-Craniofacial Journal, 51, 320-325. https://doi.org/10.1597/12-135

[19] Murray, J.C. (2002) Gene/Environment Causes of Cleft Lip and/or Palate. Clinical Genetics, 61, 248-256. https://doi.org/10.1034/j.1399-0004.2002.610402.x

[20] Jugessur, A., Shi, M., Gjessing, H.K., Lie, R.T., Wilcox, A.J., Weinberg, C.R., et al. (2009) Genetic Determinants of Facial Clefting: Analysis of 357 Candidate Genes Using Two National Cleft Studies from Scandinavia. PLoS ONE, 4, e5385. https://doi.org/10.1371/journal.pone.0005385

[21] Kondo, S., Schutte, B.C., Richardson, R.J., Bjork, B.C., Knight, A.S., Watanabe, Y., et al. (2002) Mutations in IRF6 Cause Van der Woude and Popliteal Pterygium Syndromes. Nature Genetics, 32, 285-289. https://doi.org/10.1038/ng985

[22] Grosen, D., Chevrier, C., Skytthe, A., Bille, C., Molsted, K., Sivertsen, A., et al. (2010) A Cohort Study of Recurrence Patterns among More than 54,000 Relatives of Oral Cleft Cases in Denmark: Support for the Multifactorial Threshold Model of Inheritance. Journal of Medical Genetics, 47, 162-168.

https://doi.org/10.1136/jmg.2009.069385

[23] Gowans, L.J.J., Busch, T., Mosey, P.A., Eshete, M.A., Adeyemo, W.L., Aregbesola, B., et al. (2015) The Complex Penetrance and Expressivity of IRF6 Gene in the Aetiology of Syndromic and Nonsyndromic Human Orofacial Clefts in the African Population. 7 th International Conference on Birth Defects and Disabilities in the Developing World, 21-24 September 2015, Dar Es Salaam, 103.

[24] Loenarz, C., Ge, W., Coleman, M.L., Rose, N.R., Cooper, C.D.O., Klose, R.J., et al. (2010) PHF8, a Gene Associated with Cleft Lip/Palate and Mental Retardation, Encodes an $\mathrm{N}^{\varepsilon}$-dimethyl Lysine Demethylase. Human Molecular Genetics, 19 , 217-222. https://doi.org/10.1093/hmg/ddp480 


\section{Appendix}

\section{Level of education of fathers Level of education of mothers}
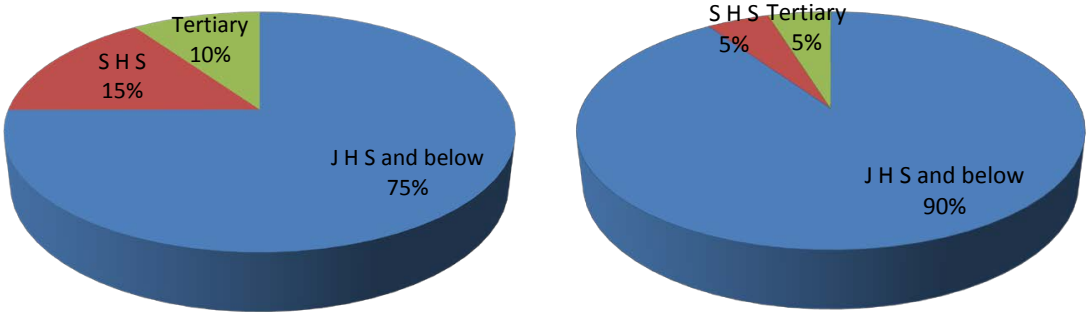

Figure S1. Level of education of parents. This figure demonstrates that at least $90 \%$ of parents from affected families never went to school or dropped out of school at the elementary level. However, the level of education of affected fathers is slightly higher than the affected mothers.

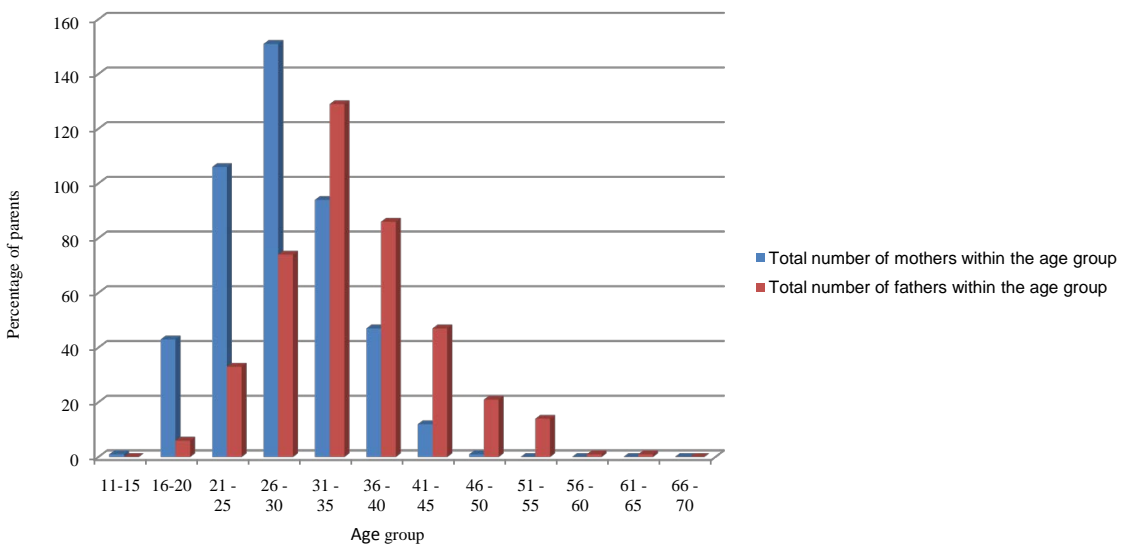

Figure S2. Age distribution of parents. Parents of affected individuals were largely in their youthful ages of less than 40 years. However, the ages of fathers were slightly higher than that of mothers. These observations suggest that old age-related gross chromosomal abnormalities may not play significant role in cleft aetiology among Ghanaians. 